\title{
ZFHX3 is indispensable for ER $\beta$ to inhibit cell proliferation via MYC downregulation in prostate cancer cells
}

Qingxia $\mathrm{Hu}^{1,2}$, Baotong Zhang $\mathbb{B}^{3}$, Rui Chen ${ }^{1}$, Changying Fu', Jun A', Xing Fu', Juan Li', Liya Fu', Zhiqian Zhang ${ }^{1}$ and Jin-Tang Dong $\mathbb{B}^{1,2,3}$

\begin{abstract}
Both estrogen receptor 2 (ESR2, also known as estrogen receptor beta (ERß)) and the zinc-finger homeobox 3 (ZFHX3, also known as ATBF1 for AT motif-binding factor 1) modulate prostate development and suppress prostatic tumorigenesis in mice. ZFHX3 is integral to proper functions of ESR1 (i.e., estrogen receptor alpha (ERa)), which belongs to the same family of proteins as ESR2, but is hardly expressed in prostate epithelial cells. It is not clear how ZFHX3 suppresses prostatic tumorigenesis. In this study, we investigated whether ZFHX3 and ER $\beta$ functionally interact with each other in the suppression of prostatic tumorigenesis. In two androgen receptor (AR)-positive prostate cancer cell lines, C4-2B and LNCaP, we first validated ERR's tumor suppressor activity indicated by the inhibition of cell proliferation and repression of MYC expression. We found that loss of ZFHX3 increased cell proliferation and MYC expression, and downregulation of MYC was necessary for ZFHX3 to inhibit cell proliferation in the same cell lines. Importantly, loss of ZFHX3 prevented ERß from suppressing cell proliferation and repressing MYC transcription. Biochemically, ERß and ZFHX3 physically interacted with each other and they both occupied the same region of the common MYC promoter, even though ZFHX3 also bound to another region of the MYC promoter. Higher levels of ZFHX3 and ERß in human prostate cancer tissue samples correlated with better patient survival. These findings establish MYC repression as a mechanism for ZFHX3's tumor suppressor activity and ZFHX3 as an indispensable factor for ERß's tumor suppressor activity in prostate cancer cells. Our data also suggest that intact ZFHX3 function is required for using ERß-selective agonists to effectively treat prostate cancer.
\end{abstract}

\section{Introduction}

Estrogen receptor 1 (ESR1) and 2 (ESR2), more commonly known as estrogen receptor alpha $(E R \alpha)$ and beta $(E R \beta)$, respectively, have diverse functions in a variety of tissues including the prostate ${ }^{1}$. While androgen and androgen receptor (AR) signaling is the driving force in prostatic carcinogenesis, estrogens and their receptors have also been implicated in the process ${ }^{2}$. ER $\beta$, in

Correspondence: Jin-Tang Dong (j.dong@emory.edu)

'Department of Genetics and Cell Biology, College of Life Sciences, Nankai University, 94 Weijin Road, 300071 Tianjin, China

${ }^{2}$ Southern University of Science and Technology, School of Medicine, 1088 Xueyuan Road, Shenzhen, Guangdong 518055, China

Full list of author information is available at the end of the article. particular, clearly plays important roles in both normal prostate development and prostatic tumorigenesis, including an inhibitory effect on the activity of AR signaling ${ }^{2}$. In normal prostates, whereas ER $\alpha$ is expressed in the stroma compartment, ER $\beta$ is predominantly expressed in the epithelium with a cellular localization to the nucleus $^{3-7}$. ER $\beta$ is indeed essential for the differentiation of epithelial cells and the maintenance of the epithelium, as knockout of Esr2 in mouse prostates causes neoplastic lesions such as hyperplasia and mouse prostatic intraepithelial neoplasia (mPIN) ${ }^{6,8}$. In addition, loss of ER $\beta$ is enough to convert epithelial cells to a mesenchymal state $^{9}$, further indicating a role of ER $\beta$ in epithelial maintenance.

\section{(c) The Author(s) 2019}

(c) (i) Open Access This article is licensed under a Creative Commons Attribution 4.0 International License, which permits use, sharing, adaptation, distribution and reproduction c. in any medium or format, as long as you give appropriate credit to the original author(s) and the source, provide a link to the Creative Commons license, and indicate if changes were made. The images or other third party material in this article are included in the article's Creative Commons license, unless indicated otherwise in a credit line to the material. If material is not included in the article's Creative Commons license and your intended use is not permitted by statutory regulation or exceeds the permitted use, you will need to obtain permission directly from the copyright holder. To view a copy of this license, visit http://creativecommons.org/licenses/by/4.0/. 
In prostatic tumorigenesis, ER $\beta$ primarily plays a suppressor role. In addition to the induction of MPIN by the loss of Esr2 in mice ${ }^{6,8}$, ER $\beta$ suppresses cell proliferation, survival, and tumor growth in human prostate cancer cell lines ${ }^{10,11}$. While ER $\beta$ 's tumor suppressor activity appears to be ligand dependent ${ }^{10,12-15}$, it is androgen independent, because such an activity is detectable in both ARpositive and -negative prostate cancer cells ${ }^{16}$. In mouse prostate tumors induced by Pten deletion, downregulation of Esr2 has been detected ${ }^{17}$, which also supports a tumor suppressor function of Esr2 in prostate cancer. In human prostate cancer, ER $\beta$ signaling appears to inhibit cell survival of TMPRSS2-ERG tumors, which usually have a more aggressive clinical phenotype ${ }^{18}$; ER $\beta$ is downregulated in some tumors ${ }^{4,7,19,20}$; and a correlation has been observed between partial loss of ER $\beta$ and castration resistance ${ }^{2}$.

How ER $\beta$ exerts a tumor suppressor function in the prostate is not well understood, even though some mechanisms have been described. For example, ER $\beta$ can upregulate FOXO3A via PUMA to induce apoptosis ${ }^{21}$; interact with KLF5 and other transcription factors to enhance FOXO1 expression to induce anoikis in ARnegative prostate cancer cells ${ }^{22}$; and attenuate the transcriptional activity of $\mathrm{AR}$ in gene expression ${ }^{23}$. In addition, some cancer-causing molecules are transcriptionally repressed by ER $\beta$, including the $M Y C$ oncogene ${ }^{24,25}$. Understanding how ER $\beta$ suppresses prostatic tumorigenesis is highly relevant to the development of therapeutic strategies in prostate cancer treatment ${ }^{26}$. For example, ER $\beta$-selective agonists are promising agents in the treatment of prostate cancer, including the most lethal castration-resistant prostate cancer (CRPC), but outcomes have been inconsistent among different $\operatorname{trials}^{27-31}$. Mechanistic information should be helpful in improving the therapeutic outcomes.

The zinc-finger homeobox 3 (ZFHX3), also known as ATBF1 for AT motif-binding factor 1, is a large transcription factor containing 23 zinc-finger domains, 4 homeodomains, and multiple other motifs ${ }^{32}$. ZFHX3 is frequently mutated in metastatic or high-grade human prostate cancers, and many of the mutations are frameshifting and thus function inactivating ${ }^{33,34}$. Specific deletion of $Z f h \times 3$ in mouse prostates not only causes mPIN but also promotes mouse prostatic tumorigenesis induced by the loss of Pten ${ }^{35,36}$. Finally, in mouse prostate tumors induced by transgenic expression of Myc or an activating mutant of AR, downregulation of $\mathrm{Zfhx} 3$ has been observed $^{37,38}$. Although these studies indicate a tumorsuppressive role of ZFHX3 in prostate cancer, it is unknown how ZFHX3 exerts such a suppressor function in prostate cancer.

Our previous studies have demonstrated that ZFHX3 modulates multiple hormonal signaling pathways, including those of estrogen $\left(\mathrm{E}_{2}\right)$-ER, progesteroneprogesterone receptor (Pg-PR), and prolactin-prolactin receptor $^{39-41}$. For example, deletion of $Z f h \times 3$ in mouse prostates alters the expression of multiple molecules involved in $\mathrm{E}_{2}$ and Pg networks ${ }^{35}$; and ZFHX3 interacts with ER $\alpha$ to modulate its functions in gene regulation and cell proliferation control in breast cancer cells ${ }^{39}$. Considering that both Zfhx 3 and ER $\beta$ are necessary for proper development of mouse prostates, both possess a tumor suppressor activity in prostate cancer, ZFHX3 interacts with $E R \alpha$ to modulate its functions, and ER $\beta$ is highly homologous to $E R \alpha$; it is reasonable to propose that ZFHX3 and ER $\beta$ interact with each other to modulate cell proliferation and tumor growth of prostate cancer cells.

In this study, we tested whether and how ER $\beta$ and ZFHX3 coordinate to function in AR-positive prostate cancer cells. Like ER $\beta$, ZFHX3 also suppressed cell proliferation and MYC expression in prostate cancer cells, and downregulation of MYC was necessary for the suppressive effect of ZFHX3 on cell proliferation. More importantly, ZFHX3 was in fact essential for ER $\beta$ to inhibit cell proliferation and MYC expression. Furthermore, ZFHX3 and ER $\beta$ interacted with each other to repress $M Y C$ transcription. These findings not only provide mechanistic insights into the tumor suppressor functions of ER $\beta$ and ZFHX3, they also have important implications for the application of ER $\beta$-selective agonists in treating prostate cancer.

\section{Results}

Validation of ER $\beta$ 's tumor suppressor activity in the LNCaP and $\mathbf{C} 4-2 \mathrm{~B}$ prostate cancer cell lines

We first surveyed the expression of ER $\alpha, E R \beta, A R$, and ZFHX3 in several prostate cancer cell lines by Western blotting (Fig. 1a). Compared to the ER $\alpha$-positive MCF-7 breast cancer cells, ER $\alpha$ was hardly detectable in any of the prostate cancer cell lines tested. On the other hand, ER $\beta$ was expressed at moderate to high levels in most prostate cancer cell lines, including the androgensensitive $\mathrm{LNCaP}$ line and its androgen-insensitive derivative lines $\mathrm{C} 4-2$ and $\mathrm{C} 4-2 \mathrm{~B}$. ZFHX3 expression was detectable in most of these cell lines as well, with C4-2, C4-2B, and LNCaP expressing higher levels, which is consistent with previous analysis of ZFHX3 messenger RNA (mRNA) $)^{34}$. As expected, AR was expressed in LNCaP, C4-2, C4-2B, and 22Rv1 cell lines (Fig. 1a). Considering that $\mathrm{LNCaP}$ and $\mathrm{C} 4-2 \mathrm{~B}$ are $\mathrm{AR}$ positive and they both expressed higher levels of ER $\beta$ and ZFHX3, we chose these two cell lines for further analyses in this study.

We then tested the effects of ER $\beta$ on cell proliferation and target gene expression in C4-2B and LNCaP cells ${ }^{13,42}$. A known agonist of ER $\beta$, diarylpropionitrile $(\mathrm{DPN})^{11,21,43,44}$, was used to activate ER $\beta$ in hormonedeprived medium (phenol red free, $5 \%$ charcoal-stripped 


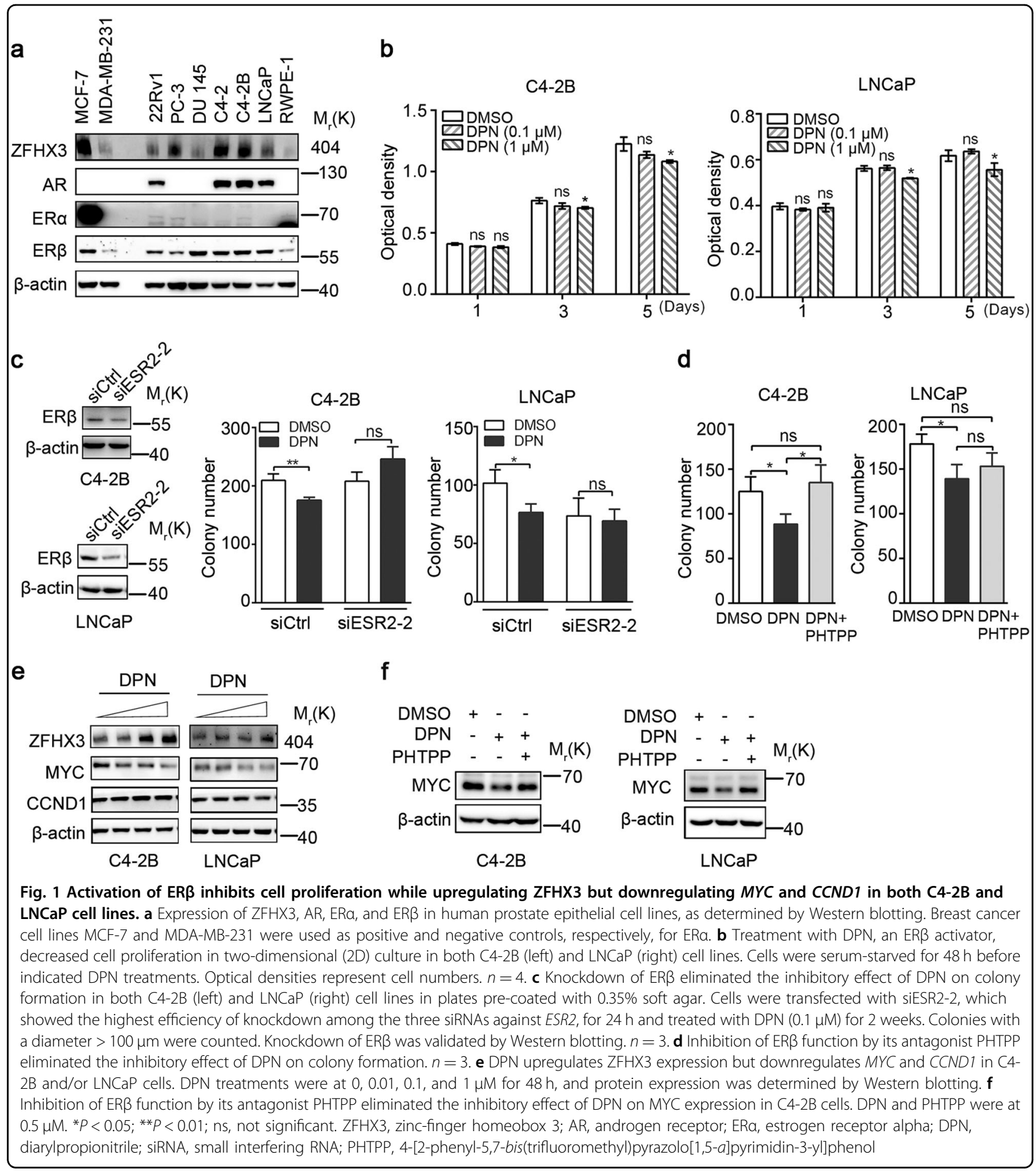

serum). In two-dimensional (2D) culture, the sulforhodamine B (SRB) assay showed that cell proliferation was reduced by DPN treatment at $1 \mu \mathrm{M}$ for 5 days in both C42B and LNCaP cells (Fig. 1b). In the 3D soft agar colony formation assay, the number of colonies was decreased in both cell lines by DPN treatment at $0.1 \mu \mathrm{M}$ (Fig. 1c), which was one-tenth of the effective concentration in the
2D SRB assay. To test the specificity of ER $\beta$ activation by DPN, we knocked down ER $\beta$ by RNA interference (RNAi), and found that knockdown of ER $\beta$ eliminated the inhibitory effect of DPN (Fig. 1c). We also used an antagonist of ER $\beta$, 4-[2-phenyl-5,7-bis(trifluoromethyl) pyrazolo[1,5-a]pyrimidin-3-yl]phenol (PHTPP), to treat cells; as expected, PHTPP treatment eliminated the 
inhibitory effect of DPN on colony formation (Fig. 1d). These results indicate that the suppressive effect of ER $\beta$ on cell proliferation also occurs in AR-positive prostate cancer cells.

ER $\beta$ exerts its tumor suppressor role in prostate cancer cells by regulating gene transcription, including the inhibition of oncogenic $M Y C$ and $C C N D 1^{24,45,46}$. As expected, activation of ER $\beta$ by DPN downregulated MYC in both C4-2B and LNCaP cells, and CCND1 in LNCaP cells (Fig. $1 \mathrm{e})$, as detected by Western blotting. Moreover, inhibition of ER $\beta$ activity by the PHTPP antagonist diminished the inhibitory effect of DPN on MYC expression in both cell lines (Fig. 1f). Considering that ER $\alpha$ regulates the expression of ZFHX $3^{39,47,48}$ and ER $\beta$ is homologous to $E R \alpha$, we also examined whether ER $\beta$ has a similar effect. Interestingly, activation of ER $\beta$ by DPN significantly upregulated ZFHX3 expression in C4-2B cells, but not in LNCaP cells (Fig. 1e). Therefore, ER $\beta$ not only downregulates $\mathrm{MYC}$ in $\mathrm{C} 4-2 \mathrm{~B}$ and $\mathrm{LNCaP}$ cells but also upregulates ZFHX3 in C4-2B cells.

\section{Loss of ZFHX3 increases cell proliferation and colony/ sphere formation in C4-2B cells}

Whereas the suppressive role of ZFHX3 in prostate cancer has been established in mouse knockout mod$\mathrm{els}^{35,36}$, the role of ZFHX3 has not been systematically examined in human prostate cancer cell lines. In this regard, we knocked out ZFHX3 in the androgenindependent but not in androgen-responsive $C 4-2 B$ cells using the CRISPR/Cas9 system. Clones with ZFHX3 deletion were isolated and confirmed for ZFHX3 disruption by sequence analysis (Fig. 2a) and Western blotting (Fig. 2b); and two clones (KO3 and KO8) were randomly selected from six confirmed clones and used for further analyses.

In the SRB assay, deletion of ZFHX3 significantly increased cell proliferation (Fig. 2c), which is consistent with our previous finding in the AR-negative PC-3 cell $\operatorname{line}^{34}$. In the sphere formation assay in Matrigel, ZFHX3null clones $\mathrm{KO} 3$ and $\mathrm{KO} 8$ not only formed larger spheres compared to the control clone (Fig. $2 \mathrm{~d}$-upper, e), they also formed significantly more spheres with a diameter $>75 \mu \mathrm{m}$ (Fig. 2f). In the soft agar assay, results were consistent, as $\mathrm{KO} 3$ and $\mathrm{KO} 8$ gave rise to many more colonies compared to the control clone (Fig. 2d-lower, g). In LNCaP cells, ZFHX3 was knocked down by RNAi (Fig. 2h), and the knockdown also facilitated colony formation in soft agar (Fig. 2i, j). These results indicate that ZFHX3 plays a suppressive role in prostate cancer cells.

\section{Suppression of colony formation by ZFHX3 depends on the downregulation of MYC}

In human prostate cancer, $M Y C$ is frequently amplified and overexpressed, while $Z F H X 3$ is frequently deleted $^{49}$. Some studies have suggested that $M Y C$ could be a target gene of $\mathrm{ZFHX} 3^{41,50}$. In mouse prostates, overexpression of $M y c$ downregulates $Z f h x 3$ expression while inducing neoplastic lesions ${ }^{38}$. Taken together with the fact that $M Y C$ is a transcriptional target of ER $\beta$ (Fig. 1$)^{24}$ and our hypothesis that ER $\beta$ and ZFHX3 function together, we tested whether ZFHX3 also downregulates MYC to suppress cell proliferation. Among LNCaP, C4-2B, and PC-3 prostate cancer cell lines, MYC expression was apparently higher in C4-2B cells (Fig. 3a). Interestingly, deletion or knockdown of ZFHX3 clearly increased MYC expression in C4-2B and LNCaP cells, as detected by Western blotting (Fig. 3b). We also detected three other ER $\beta$ transcriptional targets involved in cell proliferation, FOXO3A, CCND1, and $C D K N 1 B^{21,45,46}$, in ZFHX3-null cells, and found that loss of ZFHX3 also downregulated FOXO3A (Fig. S1a). To evaluate whether MYC upregulation mediates the role of $Z F H X 3$ deletion in cell proliferation, we used two concentrations ( 20 and $40 \mathrm{nM}$ ) of $M Y C$ small interfering RNA (siRNA) to reduce MYC expression to a level similar to $(20 \mathrm{nM})$ and lower than $(40 \mathrm{nM})$ that of wildtype control (Wt) cells (Fig. 3c). The promoting effects of ZFHX3 loss on cell proliferation and colony formation were still abrogated by the subtle knockdown of MYC (Fig. 3d, e). These results indicate that MYC upregulation by the loss of ZFHX3 plays a causal role in the promotion of cell proliferation and colony formation in prostate cancer cells.

\section{ZFHX3 physically interacts with ER $\beta$ in prostate cancer cells}

ZFHX3 interacts with $E R \alpha$, and the interaction involves via the NR-box motif (LXXLL) of $\mathrm{ZFHX3}^{39}$. Considering that ER $\beta$ and ER $\alpha$ belong to the same protein family, sharing $97 \%$ similarity in their DNAbinding domains and $59 \%$ in their ligand-binding domains, it is possible that ZFHX3 also binds to ER $\beta$ in prostate cancer cells. To test this possibility, we performed immunoprecipitation (IP) and immunoblotting (IB) assays in C4-2B cells. In the ER $\beta$ protein complexes pulled down by ER $\beta$ antibody, ZFHX3 was detected (Fig. 4a). Similar results were obtained when C4-2B cells were treated with DPN (Fig. 4b). These results suggest that endogenous ZFHX3 and ER $\beta$ physically interact with each other regardless of ER $\beta$ status. We also expressed HA-tagged ZFHX3 (HA-ZFHX3) and FLAG-tagged ER $\beta$ (Flag-ER $\beta$ ) in 293T cells and performed IP and IB with FLAG and HA antibodies. In the FLAG-ER $\beta$ complexes, HA-ZFHX3 was detected, and vice versa (Fig. 4c), further indicating an interaction between ZFHX3 and ER $\beta$.

We also expressed six overlapping fragments of ZFHX3 (Fig. 4d), which were all HA-tagged and prepared and used for mapping ZFHX3 domains 


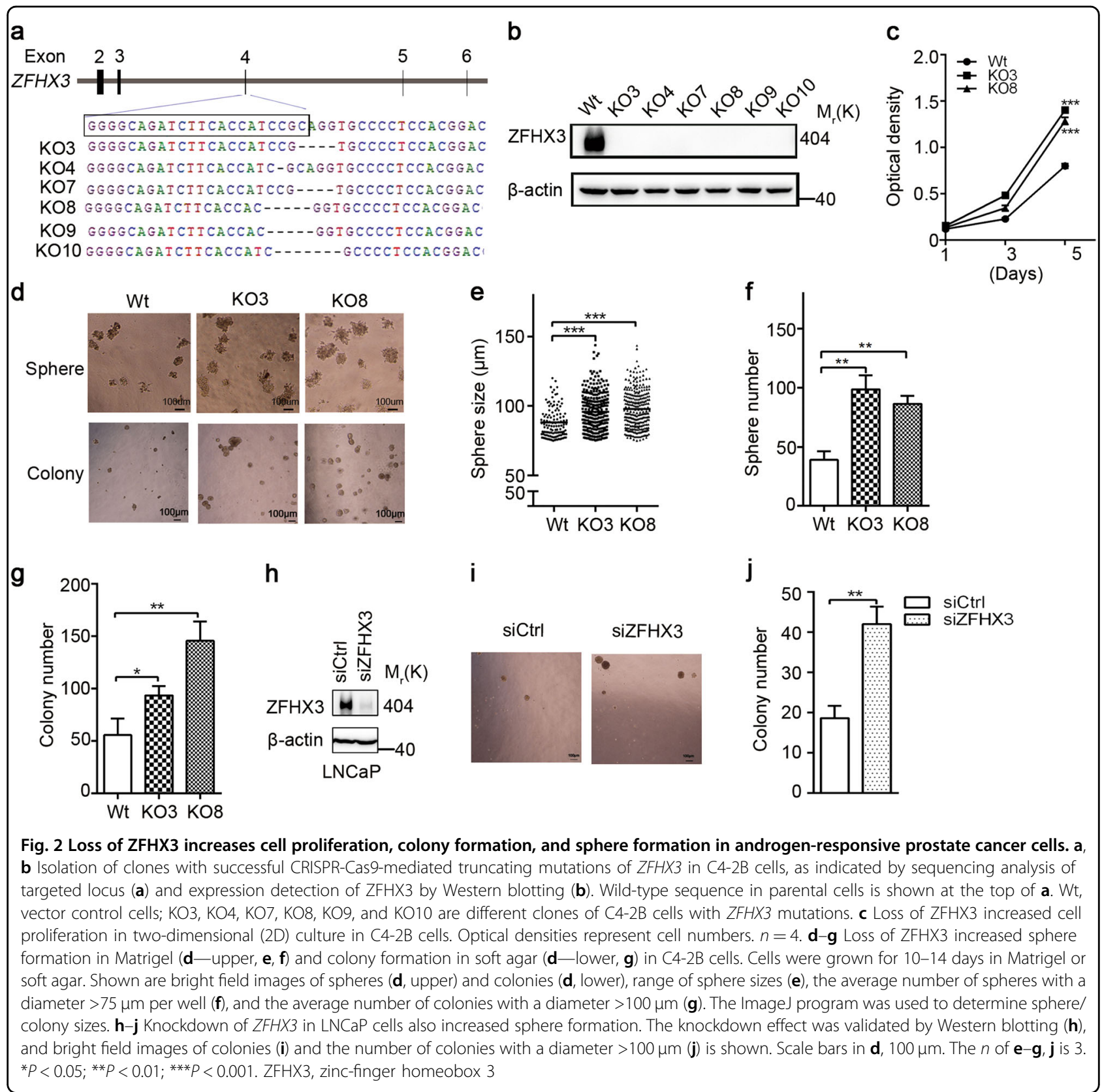

interacting with $\mathrm{ER} \alpha^{39}$, along with FLAG-tagged ER $\beta$ in 293 T cells. IP and IB demonstrated that two of the six fragments, $A$ and D, interacted with ER $\beta$ (Fig. 4e). We noticed that fragment D of ZFHX3 contained the consensus NR box and ten of its variants and fragment A contained four of its variants. The NR box and one or more of its various could be specifically recognized by $E R \beta$ and thus mediate the ZFHX3-ER $\beta$ interaction. These results further support the ZFHX3-ER $\beta$ interaction, and also define the regions of ZFHX3 involved in the interaction.

\section{ZFHX3 and ER $\beta$ cooperate to repress the transcription of $M Y C$}

Both ER $\beta$ and ZFHX3 are transcription factors that regulate MYC expression (Figs. 1 and 3), ER $\beta$ represses $M Y C$ transcription, and they interact with each other (Fig. 4$)^{34}$. It is thus likely that ZFHX3 and ER $\beta$ coordinate to repress $M Y C$ transcription. To test this prediction, we first examined the effect of DPN treatment on $M Y C$ mRNA expression in C4-2B cells using real-time PCR. A higher concentration of DPN $(1 \mu \mathrm{M})$ significantly reduced MYC mRNA level in C4-2B cells (Fig. 5a). Moreover, 

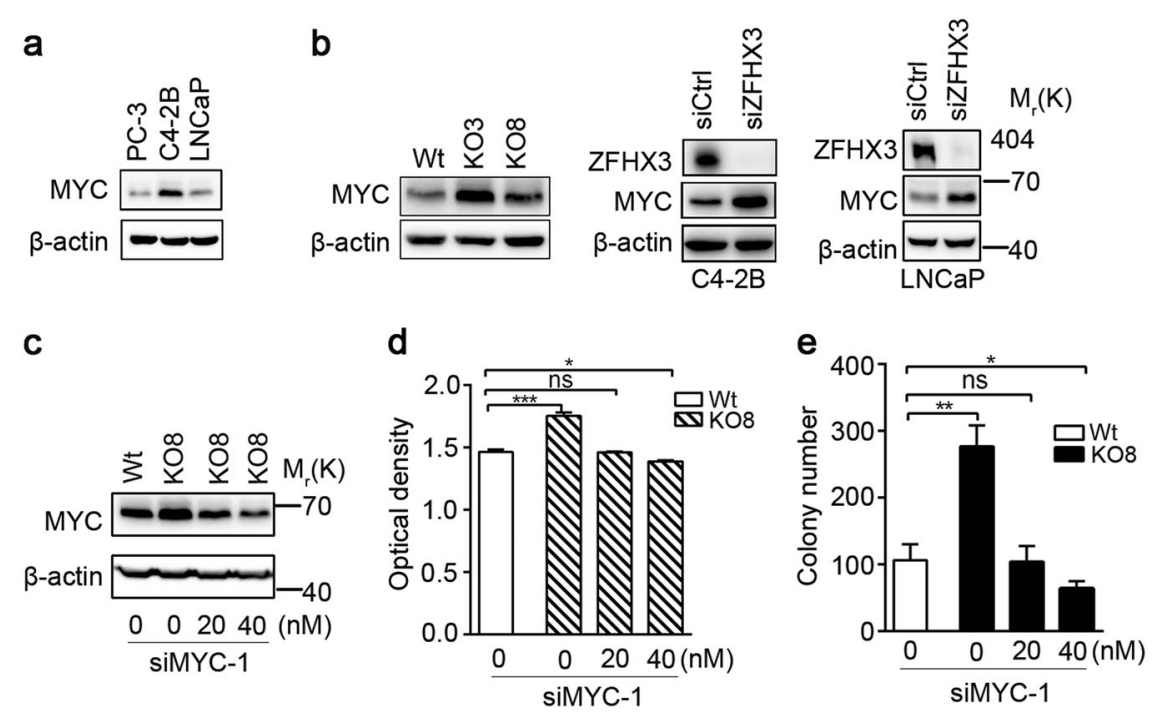

Fig. 3 Inhibitory effect of ZFHX3 on colony formation depends on the downregulation of MYC in prostate cancer cells. a Expression of MYC in prostate cancer cell lines, as detected by Western blotting. b Knockout or knockdown of ZFHX3 upregulated MYC expression in C4-2B and LNCaP cells, as detected by Western blotting. Wt, KO3, and KO8 are vector control and two ZFHX3-null clones of C4-2B. c-e Knockdown of MYC, by using siRNAs against MYC at two concentrations ( 20 and $40 \mathrm{nM}$ ), eliminated the promoting effect of ZFHX3's loss on cell proliferation and colony formation in soft agar in C4-2B cells. The SRB assay was used to measure cell proliferation (d), while the soft agar assay was used for colony formation (e). The $n$ of both $\mathbf{d}$ and $\mathbf{e}$ is $4 .{ }^{*} P<0.05$; ${ }^{*} P<0.01$; ${ }^{* *} P<0.001$; ns, not significant. ZFHX3, zinc-finger homeobox 3; siRNA, small interfering RNA; Wt, wild type; SRB, sulforhodamine B

inhibition of ER $\beta$ activity by the PHTPP antagonist reversed the inhibitory effect of DPN on MYC mRNA expression in C4-2B cells (Fig. 5b). Loss of ZFHX3, on the other hand, increased $M Y C$ mRNA level (Fig. 5c), which is consistent with MYC protein expression under the same conditions (Fig. 3).

We next conducted a luciferase promoter activity assay to test whether ZFHX3 and ER $\beta$ interact to repress $M Y C$ transcription. A longer promoter of $M Y C(2764 \mathrm{bp}$, from -2455 to $+309 \mathrm{bp}$ ) and two of its shorter fragments were cloned into the pGL3 luciferase reporter plasmid. The longer promoter had luciferase activity in control C4-2B cells, but the deletion of ZFHX3 not only dramatically increased the activity but also eliminated the inhibitory effect of DPN on the activity (Fig. 5d), consistent with the real-time PCR results (Fig. 5a, c). In parental C4-2B cells, we also transfected two shorter $M Y C$ promoter reporter plasmids, pGL3-MYC-1 and pGL3-MYC-2 (bases -2024 to -1193 for pGL3-MYC-1 and -1000 to +200 for pGL3-MYC-2). The activity of pGL3-MYC-2 was higher than that of pGL3-MYC-1, and DPN significantly inhibited the activity of pGL-MYC-2 (Fig. 5e). These results indicate that ZFHX3 is involved in the function of DPN/ ER $\beta$ signaling in the transcription of $M Y C$.

To further define the role of ZFHX3 in MYC transcription, we explored the key regions of $M Y C$ promoter that are bound by ZFHX3 and ER $\beta$ using chromatin immunoprecipitation-PCR (ChIP-PCR). Based on the finding that higher promoter activity was detected with pGL3-MYC-2, we designed three pairs of PCR primers within the MYC-2 promoter region for PCR amplification (Fig. 5f). ChIP-PCR analyses showed that ZFHX3 bound to both $\mathrm{A}$ and $\mathrm{B}$ regions of the $M Y C$ promoter, while $\mathrm{ER} \beta$ bound only to the A region (Fig. $5 \mathrm{~g}$ ). When $Z F H X 3$ was deleted, the binding of ER $\beta$ to the $M Y C$ promoter was dramatically reduced in $\mathrm{C} 4-2 \mathrm{~B}$ cells under normal culture conditions (without DPN, Fig. 5h); and DPN-increased ER $\beta$ binding to $M Y C$ promoter was eliminated under hormone-deprived conditions (Fig. 5i). These results indicate that both ZFHX3 and ER $\beta$ bind to the $M Y C$ promoter, and the binding of ER $\beta$ depends on the presence of ZFHX3.

\section{ZFHX3 is indispensable for ER $\beta$ to suppress cell proliferation and MYC expression}

Considering that ZFHX3 is necessary for ER $\beta$ to repress $M Y C$ transcription (Fig. 5), it is reasonable to propose that ER $\beta$ also depends on ZFHX3 to exert its tumor suppressor activity. We tested this hypothesis using colony formation and MYC expression as indicators. Compared to control cells with normal ZFHX3 expression, in which DPN treatment $(0.1 \mu \mathrm{M})$ significantly inhibited colony formation, loss of ZFHX3 in C4-2B cells (Fig. 6a), and knockdown of $Z F H X 3$ in LNCaP cells (Fig. 6b) not only increased colony formation but also attenuated the inhibitory effect of DPN on colony formation. Similar effects 
a

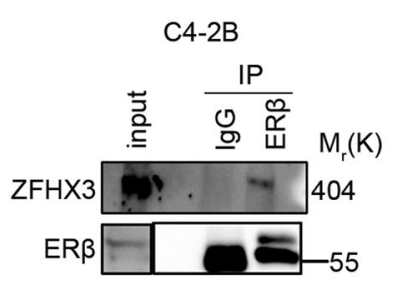

C

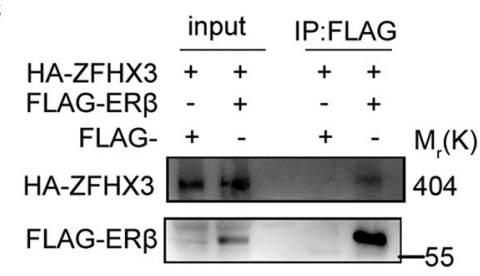

b
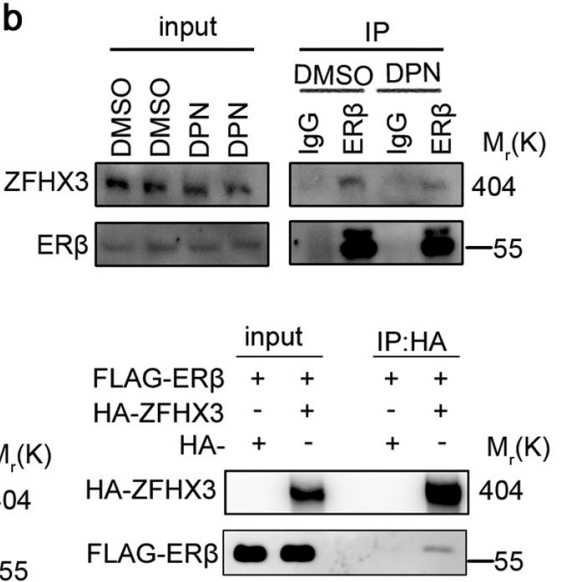

d

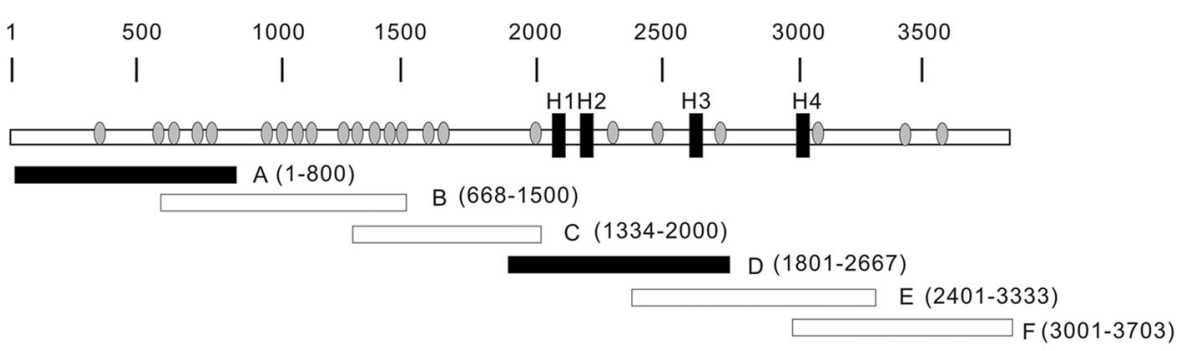

e

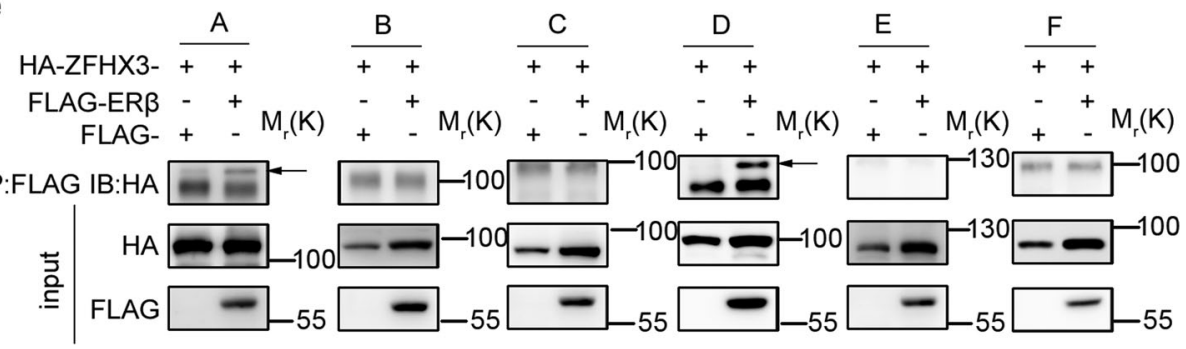

Fig. 4 ZFHX3 and ER $\beta$ physically interact with each other independent of DPN treatment. a Cell lysates from C4-2B cells, which express both ZFHX3 and ERß, were subjected to immunoprecipitation (IP) with anti-ER $\beta$ antibody and subsequent immunoblotting (IB) with anti-ZFHX3 antibody. Input indicates cell lysate not subjected to IP. b C4-2B cells were grown in phenol red-free medium with 5\% charcoal-stripped FBS for $48 \mathrm{~h}$ and then treated with DPN for $48 \mathrm{~h}$. IP and IB were performed as in a. c Expression plasmids for HA-tagged ZFHX3 (HA-ZFHX3) and FLAG-tagged ERß (FLAGERß) were transfected into $293 \mathrm{~T}$ cells. Lysates were subjected to IP with anti-FLAG or anti-HA affinity gel, and then to IB with anti-HA or anti-FLAG antibody. $\mathbf{d}$ Schematic of full ZFHX3 protein (3703 residues, horizontal bar) with 23 zinc fingers (gray ovals) and 4 homeodomains (black rectangles). The six shorter bars below indicate six overlapping fragments of ZFHX3, named A to F. Each of the six fragments was tagged with $\mathrm{HA}$, expressed in $293 T$ cells, and tested for their interactions with ERß by IP and IB. The two confirmed interactions with ER $\beta$, A and D, are shown in solid dark. e IP and $I B$ results for the interaction of FLAG-tagged ERB and each of the six HA-tagged ZFHX3 fragments. The same procedures as in $\mathbf{c}$ were used. Arrows indicate the two fragments that were pulled down by ERß (i.e., a and d). ZFHX3, zinc-finger homeobox 3; ERß, estrogen receptor beta; FBS, fetal bovine serum; DPN, diarylpropionitrile

were detected on MYC expression, as loss of ZFHX3 in C4-2B cells (Fig. 6c) and knockdown of ZFHX3 in LNCaP cells (Fig. 6d) prevented DPN from inhibiting MYC expression. Consistently, in ZFHX3-null KO8 cells, transfection-induced ZFHX3 expression not only reduced MYC expression but also sensitized cells to the inhibitory effect of DPN on MYC expression (Fig. 6e). These results indicate that ZFHX3 is indispensable for the tumor suppressor activity of ER $\beta$ in prostate cancer cells (Fig. 6f).

\section{Higher levels of ZFHX3 and ER $\beta$ correlate with better patient survival in prostate cancer}

In two cohorts of prostate cancer patients in which data are available for both gene expression and overall survi$\mathrm{val}^{51}$ or disease-free survival (DFS $)^{52}$, we examined the correlation between $Z F H X 3$ and ESR2 expression statuses with overall or disease-free survival. Patients were stratified into four groups according to the median levels of ZFHX3 and ESR2 expression: ZFHX3 high/ESR2 high, 


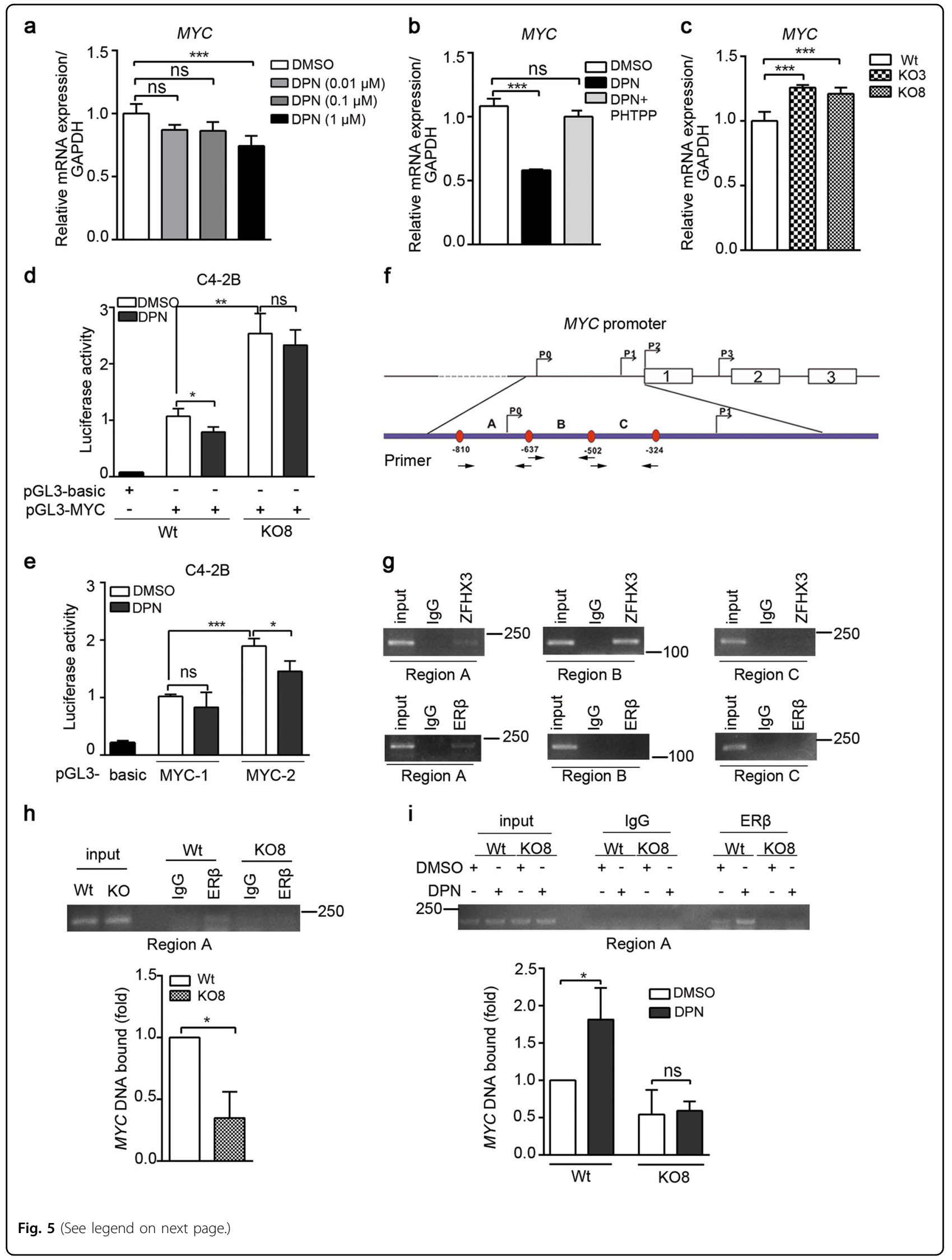


(see figure on previous page)

Fig. 5 ZFHX3 and ER $\beta$ bind to MYC promoter to coordinately repress its transcription. a DPN treatment decreased MYC mRNA level in C4-2B cells. Hormone-deprived medium was used for DPN treatment. $n=4$. $\mathbf{b}$ Inhibition of ER $\beta$ function by its antagonist PHTPP eliminated the inhibitory effect of DPN on MYC mRNA expression in C4-2B cells. DPN and PHTPP were at $0.5 \mu \mathrm{M}$. $n=4$. c Knockout of ZFHX3 increased MYC mRNA level. Wt, control clone; $\mathrm{KO} 3$ and $\mathrm{KO}$, two ZFHX3-null clones of $\mathrm{C} 4-2 \mathrm{~B}$ cells. $n=4$. d, e DPN decreased the activity of MYC promoter. Expression plasmids of pGL3 vector control (pGL3-basic), pGL3 with MYC full-length promoters (a, pGL3-MYC with bases -2455 to 309) or pGL3 with two smaller MYC promoter fragments (d, pGL3-MYC-1 with bases -2024 to -1193 and pGL3-MYC-2 with bases -1200 to -200 ), and the pRL-TR reporter were transfected into C4-2B cells in phenol red-free medium supplemented with $2 \% \mathrm{CS}-\mathrm{FBS}$. Twenty-four hours later, DPN treatments $(0.1 \mu \mathrm{M}, 48 \mathrm{~h})$ were applied, and relative luciferase activities were then determined. $n=4$. f Schematic of the MYC promoter region from base -1200 to base -200 relative to the $\mathrm{P} 2$ transcriptional initiation site (TIS), with locations of all four TISs, the first 3 exons, and primers used to amplify promoter regions $\mathrm{A}-\mathrm{C}$. Arrows under the promoter indicate primer locations. $\mathbf{g}$ Detection of ZFHX3- and ERß-bound MYC promoter DNA in parental C4-2B cells using ChIP and regular PCR. $\mathbf{h}$, $\mathbf{i}$ Binding of ER $\beta$ to MYC promoter region $A$ in the presence $(\mathrm{Wt})$ and absence (KO8) of ZFHX3 (h), with or without DPN treatment (i), using ChIP and regular PCR (upper) or real-time PCR (lower) in Wt and KO8 clones of C4-2B cells. The $n$ of $\mathbf{h}, \mathbf{i}$ is 3 . ${ }^{*} P<0.05$; ${ }^{* *} P<0.01$; ${ }^{* * *} P<0.001$; ns, not significant. ZFHX3, zinc-finger homeobox 3; ERß, estrogen receptor beta; mRNA, messenger RNA; PHTPP, 4-[2-phenyl-5,7-bis(trifluoromethyl) pyrazolo[1,5-a]pyrimidin-3-yl]phenol; Wt, wild type; CS-FBS, calf serum-fetal bovine serum; DPN, diarylpropionitrile, ChIP, chromatin immunoprecipitation

ZFHX3 high/ESR2 low, ZFHX3 low/ESR2 high, and $Z F H X 3$ low/ESR2 low. Kaplan-Meier survival analysis demonstrated that when $Z F H X 3$ expression was higher, patients with higher ESR2 had significantly better overall survival (Fig. 6g). Patients with higher $Z F H X 3$, regardless of ESR2 expression status, significantly correlated with better DFS (Fig. 6h). When ZFHX3 was lower, however, even higher ESR2 did not show a significant correlation with either overall survival or DFS (Fig. 6g, h), which is consistent with the notion that ZFHX3 is indispensable for the tumor suppressor function of ESR2.

\section{Discussion}

In this study, we examined the role of ER $\beta$ and ZFHX3 in and their interaction as a mechanism for the regulation of proliferation of AR-positive prostate cancer cells. Distinct from the oncogenic function of ER $\alpha$ in breast cancer, ER $\beta$ is abundantly expressed in the prostate and plays a tumor suppressor role in prostate cancer ${ }^{27,46,53,54}$. On the other hand, MYC appears to be involved in the functions of both $\mathrm{ER} \alpha$ and ER $\beta$, although $M Y C$ is upregulated by ER $\alpha$ in breast cancer cells and downregulated by ER $\beta$ in prostate cancer cells ${ }^{21,24,55}$. Using two AR-positive prostate cancer cell lines, C4-2B and LNCaP, we demonstrated that ER $\beta$ also has a suppressive activity in these cell lines, as indicated by SRB and colony formation assays (Fig. 1). Such a suppressive activity has been previously detected in ARnegative PC-3 and DU 145 prostate cancer cell lines ${ }^{22}$. Interestingly, analysis of two ER $\beta$ target genes involved in cell proliferation control, $M Y C$ and $C C N D 1$, showed that MYC is clearly downregulated by ER $\beta$ in the inhibition of cell proliferation in C4-2B and LNCaP cells (Fig. 1). While validating the suppressive activity of ER $\beta$ in AR-positive prostate cancer cells, these findings also indicate that downregulation of MYC also mediates ER $\beta$ 's tumor suppressor activity in AR-positive prostate cancer cells.

Our findings in this study have established ZFHX3 as an indispensable factor for the tumor suppressor activity of
ER $\beta$. The most supportive evidence is that loss or downregulation of ZFHX3 in $\mathrm{C} 4-2 \mathrm{~B}$ or $\mathrm{LNCaP}$ cells eliminated the inhibitory effect of DPN/ER $\beta$ on colony formation and MYC expression (Fig. 6). Consistent with this, re-expression of ZFHX3 in ZFHX3-null cells sensitized cells to the inhibitory effect of DPN/ER $\beta$ on MYC expression (Fig. 6). Further supporting the necessity of ZFHX3 for ER $\beta$ 's tumor suppressor activity, we found that ER $\beta$ and ZFHX3 cooperate to repress the transcription of $M Y C$. For example, ER $\beta$ physically interacts with ZFHX3 in prostate cancer cells via multiple domains of ZFHX3, as revealed by IP and IB analyses (Fig. 4); the same promoter site of $M Y C$ can be bound by both ER $\beta$ and ZFHX3, and loss of ZFHX3 prevented ER $\beta$ from binding to the site (Fig. 5). Loss of ZFHX3 also reduced the expression of FOXO3A (Fig. S1a), an apoptosis-promoting factor that is upregulated by ER $\beta^{21}$. Therefore, ZFHX3 inhibits cell proliferation likely by regulating multiple genes including both $M Y C$ and FOXO3A.

At present, it is unknown which other transcription factors are involved in the ER $\beta$-ZFHX3 interaction. For example, a previous study demonstrated that ER $\beta$ interacts with KLF5 and CBP to induce FOXO1 transcription to suppress the proliferation of AR-negative prostate cancer cells ${ }^{21}$, but it is unknown whether KLF5 and CBP are also involved in the ER $\beta$-ZFHX3 interaction in AR-positive prostate cancer cells. This mechanism is in addition to the previously reported mechanisms for $E R \beta$, including the interaction with KLF5 and other co-factors to enhance FOXO1 expression to induce anoikis ${ }^{22}$.

ZFHX3 has been established as a tumor suppressor in prostate cancer in our previous studies, as its gene undergoes frequent somatic mutations in advanced prostate cancer ${ }^{33,34}$ and its deletion in mouse prostates causes neoplastic lesions and promotes Pten deletioninduced tumorigenesis ${ }^{35,36}$. Findings in this study provide additional evidence for a tumor suppressor activity of 
a

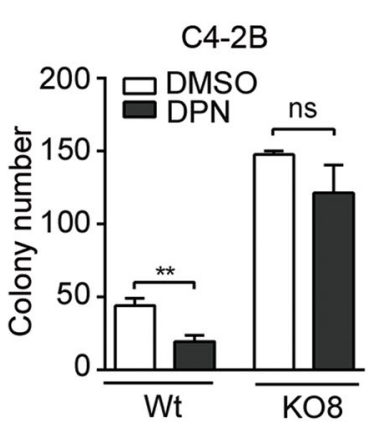

C

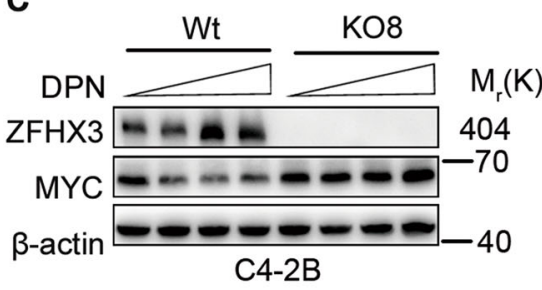

e
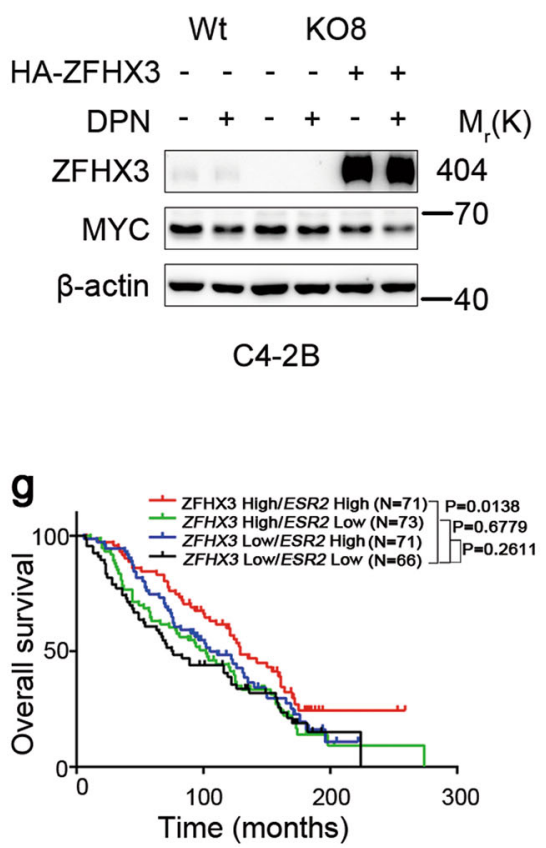

b

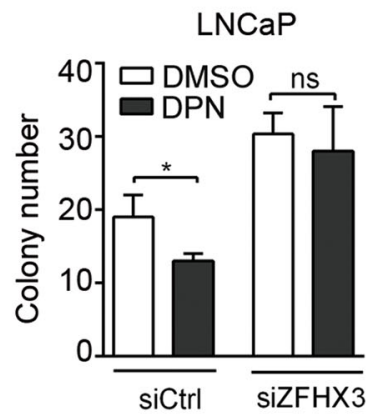

d

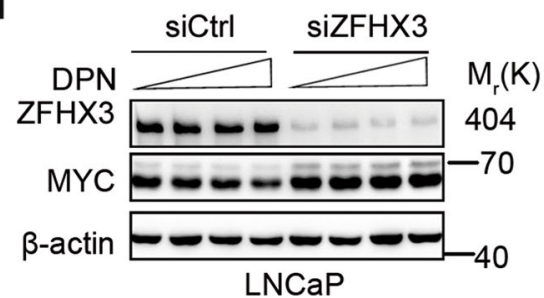

f

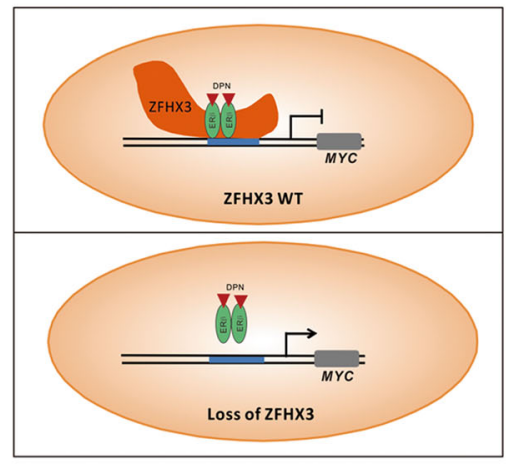

h

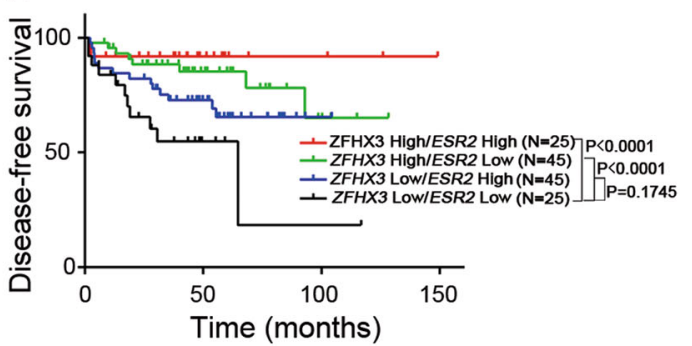

Fig. 6 Loss of ZFHX3 eliminated the inhibitory effect of ER $\beta$ on colony formation and MYC expression in prostate cancer cells and correlated with worse patient survival. C4-2B (a, c) and LNCaP (b, d) cells were used for both colony formation assay (a, b) and MYC expression analysis (c, d). In colony formation assay, cells plated on $0.35 \%$ soft agar in phenol red-free medium were cultured, and colonies $>100 \mu \mathrm{m}$ were counted. MYC protein was detected by Western blotting. DPN was added to enhance the ER $\beta$ activity. e Transfection-mediated re-expression of ZFHX3 in the ZFHX3-null KO8 clone of C4-2B cells decreased MYC expression, as detected by Western blotting. $\mathbf{f} A$ model for how ZFHX3 is indispensable for ER $\beta$ to suppress cell proliferation and tumor growth in prostate cancer cells. In the presence of ZFHX3, ERß interacts with ZFHX3 to repress the transcription of MYC and other oncogenes, but this repression is eliminated by the loss of ZFHX3. $\mathbf{g}, \mathbf{h}$ Kaplan-Meier analysis of overall survival $(\mathbf{g})$ and disease-free survival $(\mathbf{h})$ of prostate cancer patients with different statuses of ZFHX3 and ESR2 expression. The $n$ of $\mathbf{a}, \mathbf{b}$ is $3 .{ }^{*} P<0.05$; ${ }^{* *} P<0.01$; ns, not significant. ZFHX3, zinc-finger homeobox 3; ERß, estrogen receptor beta; DPN, diarylpropionitrile

ZFHX3 in AR-positive prostate cancer cells, as indicated by assays of SRB, colony formation in soft agar, and sphere formation in Matrigel (Fig. 2).
Although ZFHX3 is clearly tumor suppressive in prostate cancer, how it exerts its tumor suppressor function was unknown. Our findings indicate that being part of 
ER $\beta$ signaling is an important mechanism for ZFHX3's tumor suppressor activity in prostate cancer, as ZFHX3 is clearly upregulated by activated ER $\beta$ in C4-2B cells (Fig. 1), and repression of $M Y C$ transcription by ER $\beta$ required the interaction of ER $\beta$ with ZFHX3 (Figs. 4 and 5). However, $E R \beta$ is not required for ZFHX3 to suppress cell proliferation, as loss of ZFHX3 alone increased the formation of colonies and spheres in complete medium (Fig. 2); and even in the absence of hormones (charcoal-stripped serum and phenol red-free medium), loss of ZFHX3 still increased colony formation (Fig. 6). Therefore, other unknown mechanisms are also responsible for ZFHX3's tumor suppressor activity in prostate cancer cells.

MYC is a well-established oncoprotein that plays a driving role in the development and progression of multiple types of cancers including prostate cancer. For example, $M Y C$ is frequently amplified and overexpressed in human prostate cancer ${ }^{49}$, and transgenic overexpression of $M y c$ in mouse prostates not only induces prostate tumors but also promotes tumor progression ${ }^{38}$. In human malignancies, genomic amplification is one mechanism for $M Y C$ s overexpression, but abnormalities in multiple signaling pathways also upregulate $M Y C$ expression ${ }^{56}$. Although ER $\beta$ clearly downregulates $M Y C$ in prostate cancer cell lines ${ }^{24}$ and MYC promoter contains consensus ZFHX3 binding sites $^{50}$, our findings for the first time demonstrate that $M Y C$ transcription is indeed repressed by ZFHX3 in prostate cancer cells. For example, loss of ZFHX3 dramatically increased MYC expression in both $\mathrm{C} 4-2 \mathrm{~B}$ and $\mathrm{LNCaP}$ prostate cancer cells (Fig. 3), and ZFHX3 clearly bound to the $M Y C$ promoter (Fig. 5). Although one region of the $M Y C$ promoter was bound by both ZFHX3 and ER $\beta$, another region was only bound by ZFHX3 and not by ER $\beta$ (Fig. 5), further indicating that ZFHX3 is a bona fide repressor of $M Y C$ transcription in prostate cancer cells.

Importantly, repression of $M Y C$ indeed plays a causal role in ZFHX3-mediated suppression of cell proliferation in prostate cancer, as silencing MYC in C4-2B cells prevented $Z F H X 3$ deletion from increasing cell proliferation in both SRB and colony formation assays (Fig. 3), and this remained true even when $M Y C$ expression was slightly reduced to a level comparable to that of control cells (Fig. 3). Therefore, MYC upregulation plays a causal role in the promotion of cell proliferation and colony formation by the loss of ZFHX3 in prostate cancer cells.

ER $\beta$-selective agonists have been tested as therapeutic agents in the treatment of prostate cancer, including the most lethal form, $\mathrm{CRPC}^{27-31}$, and because ER $\beta$ has tumor suppressor activity, it is frequently downregulated $^{4,7,19,20,27,53,54}$, partial loss of ER $\beta$ correlates with castration resistance ${ }^{2}$, and such agonists upregulate ER $\beta$ expression $^{57}$. Indeed, an inhibitory effect of ER $\beta$ agonists on AR activity, cell proliferation, and tumor growth have been demonstrated ${ }^{8,28,31,58}$, and activation of ER $\beta$ also appears to enhance the effect of androgen deprivation therapy in an experimental system ${ }^{59}$. However, while findings from some preclinical studies are encouraging $^{16,28}$, other findings are conflicting ${ }^{60,61}$ and have reported a lack of effect ${ }^{60-62}$. For ZFHX3, its loss of function is relatively common in advanced prostate cancer, as $Z F H X 3$ is one of the most frequently mutated genes in prostate cancer; most tumors carrying ZFHX3 mutations are metastases, high-grade tumors, and/or castration-resistant tumors; and many of the mutations are truncating mutations ${ }^{19,33,34}$. Our finding of ZFHX3 as an indispensable factor for ER $\beta$ function in this study suggests that the status of ZFHX3 needs to be considered when restoring or enhancing ER $\beta$ activity via its agonists for the treatment of prostate cancer. Without ZFHX3, ER $\beta$ would not be able to suppress cell proliferation and tumor growth. Consistent with this, when ZFHX3 expression is higher, higher ER $\beta$ expression significantly correlates with both overall survival and DFS, but when ZFHX3 expression is lower, this correlation is absent (Fig. $6 \mathrm{~g}, \mathrm{~h}$ ). The same consideration applies to the approach of using ER $\beta$ as a predictive biomarker for endocrine treatment, which has also been inconclusive at this time ${ }^{63}$.

ZFHX3 coordinates with multiple hormone signaling pathways. For example, ER $\alpha$ not only regulates the expression of ZFHX3 but also interacts with ZFHX3 to regulate gene expression and cell proliferation in breast cancer cells ${ }^{39}$. Additionally, progesterone signaling upregulates the transcription of $Z F H X 3$ in breast epithelial cells $^{40}$, and ZFHX3 is in turn essential for Pg-PR) to function in mouse mammary gland development ${ }^{64}$. We have demonstrated in this study that ZFHX3 is indispensable for ER $\beta$ signaling to suppress cell proliferation and repress $M Y C$ transcription. It is thus likely that ZFHX3 is also a regulator of androgen/AR signaling in prostate cancer. Currently, we are testing whether this is the case. We are also dissecting the biochemical basis of ZFHX3-ER $\beta / E R \alpha / P R$ interactions.

In summary, we examined the relationship between two established transcription factors that are not only essential for normal prostate development but are also tumor suppressors in prostatic tumorigenesis, ER $\beta$ and ZFHX3. Using AR-positive prostate cancer cell lines, in which the suppressive activities of ER $\beta$ in cell proliferation and MYC expression were validated, we demonstrated that loss of ZFHX3 also increased cell proliferation and MYC expression, and downregulation of MYC was necessary for ZFHX3 to inhibit cell proliferation. Importantly, loss of ZFHX3 prevented ER $\beta$ from suppressing cell proliferation and repressing $M Y C$ transcription, and the necessity for ZFHX3 was due to its interaction with ER $\beta$ and their binding to the promoter of $M Y C$ (Fig. 6f). These findings provide novel insights into the development and progression of prostate cancer. 


\section{Materials and methods}

\section{Cell culture, transfection, and reagents}

Human embryonic kidney 293T cells, purchased from ATCC (Manassas, VA, USA), were cultured in Dulbecco's modified Eagle's mMedium medium (Gibco, Waltham, MA, USA) supplemented with $10 \%$ fetal bovine serum (FBS; Gibco). Human prostate cancer cell lines C4-2B (gift of Dr. Leland Chung, Cedar Sinai Medical Center, VA, USA) and LNCaP (purchased from ATCC) were cultured in RPMI-1640 medium (Gibco) supplemented with $10 \%$ FBS. The identities of LNCaP, C4-2B, and clones derived from $\mathrm{C} 4-2 \mathrm{~B}$ were confirmed by short tandem repeat (STR) analysis. During experiments, cells recovered from a liquid nitrogen freezer were used within 2 months (<20 passages) with no noticeable morphological changes. For all experiments involving DPN or PHTPP treatments, the medium was replaced with phenol red-free medium containing 5\% charcoalstripped FBS $24 \mathrm{~h}$ before transfection. The same medium was replaced $24 \mathrm{~h}$ after transfection. DPN and PHTPP were purchased from Abcam (Cambridge, MA, USA), soft agar from Lonza (Rockland, ME, USA), and Matrigel from BD Biosciences (Bedford, MA, USA).

For gene silencing by RNAi, cells were transiently transfected with siRNAs using the Lipofectamine RNAiMAX reagent according to the manufacturer's instructions (Invitrogen, Carlsbad, CA, USA). We used siRNAs from Invitrogen for the knockdown of ESR2 (RNA-Stealth Select Oligos set, Cat\# 1299003). For MYC silencing, two siRNAs (Supplementary Table 1) were synthesized by Sangon Biotech (Shanghai, China). The efficiency of RNAi was evaluated by Western blotting (Supplementary Figure S1). Among the three siRNAs against ESR2, siESR-2 showed the highest efficiency of knockdown and was used throughout the study. For the two siRNAs against $M Y C$, both were effective, and MYC-1 was used in other experiments. The siRNA against ZFHX3 was from a previous study ${ }^{39}$.

Plasmid transfection was performed with Lipofectamine 2000 (Invitrogen).

\section{Plasmids}

Mammalian expression plasmids for pCDNA3-FLAG$E R \beta$ and promoter plasmid for pGL3-MYC and pGL3MYC-1 were generated using a PCR-based approach with primers listed in Supplementary Table 2. The pGL3-MYC-2 was kindly provided by Dr. Lihong Ye of Nankai University.

\section{Cell proliferation assay}

C4-2B cells were seeded into 24-well tissue culture plates at $5 \times 10^{4}$ cells per well and collected every day or every 3 days. The cells were fixed with $10 \%$ trichloroacetic acid for $1 \mathrm{~h}$ at $4{ }^{\circ} \mathrm{C}$, washed three times with distilled water, and stained with $100 \mu \mathrm{l}$ SRB solution $(0.4 \%$ SRB diluted in $1 \%$ acetic acid) for $1 \mathrm{~h}$. Afterwards, plates were washed three times with $1 \%$ acetic acid and air dried. The stained cells were dissolved with $10 \mathrm{mM}$ Tris- $\mathrm{HCl}$ buffer ( $\mathrm{pH}$ 8.5), and absorbance was measured. Experiments were performed in triplicate.

\section{Soft agar colony formation assay}

Following previously published procedures ${ }^{22,65}, \mathrm{C} 4-2 \mathrm{~B}$ and LNCaP cells were cultured in RPMI-1640 medium with $10 \%$ FBS or phenol red-free RPMI-1640 with $2-5 \%$ charcoal-stripped FBS. Two to five thousand cells were suspended in $0.35 \%$ agar with or without DPN, and layered on top of $1.5 \mathrm{~mL}$ of RPMI-1640 solidified with $0.6 \%$ agar in each well of a 6-well plate. After incubation at $37^{\circ} \mathrm{C}$ in an $\mathrm{CO}_{2}$ incubator for 2 weeks, colonies with a $>100 \mu \mathrm{m}$ were imaged and counted with the ImageJ program. The assay was conducted in triplicate in each experiment, and each experiment was repeated twice.

\section{Sphere formation assay}

The sphere formation assay has been previously described $^{66}$. Briefly, $40 \mu \mathrm{L}$ of growth factor reduced Matrigel was added to each well of 8-well glass chamber slides and spread evenly. After Matrigel was solidified for $15 \mathrm{~min}$ at $37^{\circ} \mathrm{C}, 400 \mu \mathrm{L}$ of cell suspension (2000 cells) in RPMI-1640 medium containing 10\% FBS and 2\% Matrigel was seeded into each well, and the medium was replaced every 3 days. Images of spheres with defined sizes were subjected to the ImageJ computer program. Spheres with a diameter larger than $75 \mu \mathrm{m}$ were counted.

\section{Immunoprecipitation and Western blotting}

Cultured cells with indicated treatments were washed twice with ice-cold phosphate-buffered saline (PBS) and then lysed in modified radioimmune precipitation assay buffer $(150 \mathrm{mM} \mathrm{NaCl}, 50 \mathrm{mM}$ Tris- $\mathrm{HCl}, \mathrm{pH} 7.5,1 \%$ NP40 , and protease inhibitor mixture). Cell lysates were centrifuged to collect supernatants, which were first incubated overnight with different antibodies and then with protein A/G-agarose (Invitrogen) with rotation at $4{ }^{\circ} \mathrm{C}$ for another $2 \mathrm{~h}$. After washing three times with modified radioimmune precipitation assay buffer, immunoprecipitates were released by boiling for $10 \mathrm{~min}$ in $50 \mu \mathrm{L}$ loading buffer, resolved in $4-10 \%$ sodium dodecyl sulfate-polyacrylamide gel electrophoresis, and then blotted with different antibodies (details of the antibodies are listed in Supplementary Table 3). Horseradish peroxidase- conjugated secondary antibodies and goat antirabbit immunoglobulin G (IgG) or goat anti-mouse IgG were diluted at 1:5000. Signals were detected by Western Bright ECL (Advansta, Menlo Park, CA, USA), and blots were photographed with the luminescent image analyzer (Jun Yi Dong Fang, Beijing, China). 


\section{Genome engineering for ZFHX3 truncation}

ZFHX3-specific single guide RNA (sgRNA) oligos were designed following the published protocol ${ }^{67}$ and cloned into the LentiCRISPR, which was kindly provided by Dr. Yushan Zhu. The following pairs of sgRNA were used: 5'CACCGGGCAGATCTTCACCATCCGC-3' (forward) and 5'-AAACGCGGATGGTGAAGATCTGCCC-3' (reverse). Lentiviral particles were produced in 293T cells by cotransfecting pLKO.1 with pMD2.G and psPAX2 plasmids using the FuGENE 6 transfection reagent (Promega, Madison, WI, USA) according to the manufacturer's protocol. Six hours after transfection, the medium was replaced, and cells were incubated for an additional 2 days before viral supernatant was collected. Human C4-2B cells were seeded in 6-well culture plates and grown to about $70 \%$ confluency. Culture medium was then replaced with $2 \mathrm{~mL}$ of fresh medium containing $8 \mu \mathrm{g} / \mathrm{mL}$ of polybrene and $1 \mathrm{~mL}$ of lentiviral supernatant. Six to $12 \mathrm{~h}$ after viral infection, the lentivirus-containing medium was replaced with fresh medium containing puromycin (Sigma, St Louis, MO, USA) at $3 \mu \mathrm{g} / \mathrm{mL}$, and the incubation continued for 3-5 days to select cells stably expressing sgRNAs. Cells were then seeded into 96-well plates at 0.5 cells/well, and single-cell clones were collected and identified by DNA sequencing and Western blotting analysis.

\section{Chromatin IP assay}

C4-2B cells were grown for 3 days in phenol red-free RPMI-1640 medium supplemented with $2 \%$ charcoalstripped FBS and treated with either vehicle or $100 \mathrm{nM}$ DPN for $45 \mathrm{~min}$. ChIP assay was performed according to the manufacturer's instruction using the SimpleChIP Enzymatic Chromatin IP Kit (Magnetic Beads) from Cell Signaling Technology (Danvers, MA, USA). Briefly, cells were cross-linked with $1 \%$ formaldehyde for $10 \mathrm{~min}$ at room temperature. Glycine quenched samples were washed with ice-cold PBS. Cells were then lysed, and nuclei were separated. Micrococcal nuclease was added to digest DNA for $20 \mathrm{~min}$ at $37^{\circ} \mathrm{C}$, and digestion reactions were stopped by adding $0.5 \mathrm{M}$ EDTA. The nuclear pellet was collected and incubated in ChIP buffer with protease inhibitors for $10 \mathrm{~min}$ on ice. Sheared cross-linked chromatin preparation was collected after sonication. Chromatin extracts were immunoprecipitated by ZFHX3 or ER $\beta$ antibody using normal rabbit IgG or mouse IgG as a negative control. Quantitative real-time PCR was performed using the Realplex real-time PCR detection system (Eppendorf, Hamburg, Germany). Sequences of primers are described in Supplementary Table 4.

\section{Reverse transcription and real-time PCR}

Total RNA was isolated using the TRIzol reagent (Invitrogen) according to the manufacturer's protocol and was used for complementary DNA synthesis with the Moloney murine leukemia virus reverse transcriptase system (Promega). Real-time PCR was performed using the Mastercycler ep Realplex system (Eppendorf) using the SYBR premix Ex Taq (TaKaRa Bio Inc., Tianjin, China). Primer sequences were as follows: $5^{\prime}$-GGTGGTCTCCTCTGAC TTCAACA-3' (GAPDH forward), 5'-GTTGCTGTAGC CAAATTCGTTGT-3' (GAPDH reverse), 5'-GTCAA GAGGCGAACACACAAC-3' (MYC forward), and 5' -TTG GACGGACAGGATGTATGC-3' (MYC reverse).

\section{Luciferase reporter gene assays}

C4-2B cells were transiently transfected with pGL3, pGL3-MYC, or pGL3-MYC-1/2 plasmid and the pRT-TK Renilla luciferase plasmid (Promega). Luciferase activities were determined $48 \mathrm{~h}$ after transfection and DPN treatments using the Dual-Luciferase Reporter Gene Assay Kit (Promega). Luciferase activity was normalized to Renilla luciferase activity in each reaction. Experiments were performed in triplicate.

\section{Correlation between ZFHX3/ESR2 expression and patient survival and other statistical analyses}

Two previously published cohorts of prostate cancer patients were used for survival analysis. One included 281 men who either died of prostate cancer or survived for more than 10 years without metastases ${ }^{51}$, and the other included 140 prostate cancers that had both mRNA expression data and disease-free survival status ${ }^{52}$. Survival curves were prepared by using the Kaplan-Meier analysis, and the statistical parameters were calculated by a logrank test.

All experiments were repeated at least twice, unless stated otherwise. All experimental readings were expressed as mean \pm standard errors. Means were compared with one-way analysis of variance or two-way analysis of variance when applicable. Multiple comparisons were performed by Tukey's multiple comparisons test and $P$ values $<0.05$ were considered as statistically significant. All statistical analyses were conducted using the SPSS 21 package (IBM Analytics, Armonk, NY, USA).

\footnotetext{
Acknowledgements

This work was supported by grant 81472464 from the National Natural Science Foundation of China (NSFC). We thank Dr. Anthea Hammond of Emory

University for editing the manuscript and Dr. Dan Zhao in the lab for helpful comments and assistance during the study.

\section{Author details}

${ }^{1}$ Department of Genetics and Cell Biology, College of Life Sciences, Nankai University, 94 Weijin Road, 300071 Tianjin, China. ${ }^{2}$ Southern University of Science and Technology, School of Medicine, 1088 Xueyuan Road, Shenzhen, Guangdong 518055, China. ${ }^{3}$ Department of Hematology and Medical Oncology, Emory Winship Cancer Institute, Emory University School of Medicine, 1365C Clifton Road, Atlanta, GA 30322, USA
}

\section{Authors' contributions}

Q.H. and J.-T.D. conceived the project, designed experiments, and analyzed all data. B.Z. designed some experiments and worked on the manuscript. Q.H., R. 
C., C.F., J.L. and L.F. performed experiment. J.A. and X.F. analyzed gene expression and survival data of prostate cancer patients. Q.H. prepared, Z.Z. revised and J.-T.D. revised and finalized the manuscript.

\section{Conflict of interest}

The authors declare that they have no conflict of interest.

\section{Publisher's note}

Springer Nature remains neutral with regard to jurisdictional claims in published maps and institutional affiliations.

Supplementary information accompanies this paper at (https://doi.org/ 10.1038/s41389-019-0138-y).

Received: 10 January 2019 Accepted: 20 March 2019

Published online: 12 April 2019

\section{References}

1. Imamov, O., Shim, G. J., Warner, M. \& Gustafsson, J. A. Estrogen receptor beta in health and disease. Biol. Reprod. 73, 866-871 (2005).

2. Bonkhoff, H. Estrogen receptor signaling in prostate cancer: Implications for carcinogenesis and tumor progression. Prostate 78, 2-10 (2018).

3. Prins, G. S. et al. Estrogen receptor-beta messenger ribonucleic acid ontogeny in the prostate of normal and neonatally estrogenized rats. Endocrinology $\mathbf{1 3 9}$, 874-883 (1998).

4. Leav, I. et al. Comparative studies of the estrogen receptors beta and alpha and the androgen receptor in normal human prostate glands, dysplasia, and in primary and metastatic carcinoma. Am. J. Pathol. 159, 79-92 (2001).

5. Prins, G. S. et al. Estrogen imprinting of the developing prostate gland is mediated through stromal estrogen receptor alpha: studies with alphaERKO and betaERKO mice. Cancer Res. 61, 6089-6097 (2001).

6. Weihua, Z., Warner, M. \& Gustafsson, J. A. Estrogen receptor beta in the prostate. Mol. Cell. Endocrinol. 193, 1-5 (2002).

7. Fixemer, T., Remberger, K. \& Bonkhoff, H. Differential expression of the estrogen receptor beta (ERbeta) in human prostate tissue, premalignant changes, and in primary, metastatic, and recurrent prostatic adenocarcinoma. Prostate 54, 79-87 (2003).

8. Weihua, Z. et al. A role for estrogen receptor beta in the regulation of growth of the ventral prostate. Proc. Natl Acad. Sci. USA 98, 6330-6335 (2001).

9. Mak, P. et al. ERbeta impedes prostate cancer EMT by destabilizing HIF-1alpha and inhibiting VEGF-mediated snail nuclear localization: implications for Gleason grading. Cancer Cell 17, 319-332 (2010).

10. Cheng, J., Lee, E. J., Madison, L. D. \& Lazennec, G. Expression of estrogen receptor beta in prostate carcinoma cells inhibits invasion and proliferation and triggers apoptosis. FEBS Lett. 566, 169-172 (2004).

11. Colciago, A. et al. In vitro chronic administration of ERbeta selective ligands and prostate cancer cell growth: hypotheses on the selective role of 3betaadiol in AR-positive RV1 cells. Biomed. Res. Int. 2014, 801473 (2014).

12. Guerini, V. et al. The androgen derivative 5alpha-androstane-3beta,17beta-diol inhibits prostate cancer cell migration through activation of the estrogen receptor beta subtype. Cancer Res. 65, 5445-5453 (2005).

13. Hurtado, A. et al. Estrogen receptor beta displays cell cycle-dependent expression and regulates the G1 phase through a non-genomic mechanism in prostate carcinoma cells. Cell Oncol. 30, 349-365 (2008).

14. Walton, T. J. et al. DNA demethylation and histone deacetylation inhibition cooperate to re-express estrogen receptor beta and induce apoptosis in prostate cancer cell-lines. Prostate 68, 210-222 (2008).

15. Dondi, D. et al. Estrogen receptor beta and the progression of prostate cancer: role of 5alpha-androstane-3beta, 17beta-diol. Endocr. Relat. Cancer 17, 731-742 (2010).

16. McPherson, S. J. et al. Estrogen receptor-beta activated apoptosis in benign hyperplasia and cancer of the prostate is androgen independent and TNFalpha mediated. Proc. Natl Acad. Sci. USA 107, 3123-3128 (2010).

17. Mak, P. et al. Prostate tumorigenesis induced by PTEN deletion involves estrogen receptor beta repression. Cell Rep. 10, 1982-1991 (2015).

18. Setlur, S. R. et al. Estrogen-dependent signaling in a molecularly distinct subclass of aggressive prostate cancer. J. Natl Cancer Inst. 100, 815-825 (2008).
19. Royuela, M. et al. Estrogen receptors alpha and beta in the normal, hyperplastic and carcinomatous human prostate. J. Endocrinol. 168, 447-454 (2001).

20. Asgari, M. \& Morakabati, A. Estrogen receptor beta expression in prostate adenocarcinoma. Diagn. Pathol. 6, 61 (2011).

21. Dey, P., Strom, A. \& Gustafsson, J. A. Estrogen receptor beta upregulates FOXO3a and causes induction of apoptosis through PUMA in prostate cancer. Oncogene 33, 4213-4225 (2014).

22. Nakajima, Y. et al. Estrogen regulates tumor growth through a nonclassical pathway that includes the transcription factors ERbeta and KLF5. Sci. Signal. 4 , ra22 (2011).

23. Paech, K. et al. Differential ligand activation of estrogen receptors ERalpha and ERbeta at AP1 sites. Science 277, 1508-1510 (1997).

24. Dey, P. et al. Estrogen receptors beta1 and beta2 have opposing roles in regulating proliferation and bone metastasis genes in the prostate cancer cell line PC3. Mol. Endocrinol. 26, 1991-2003 (2012).

25. Vivar, O. I. et al. Estrogen receptor beta binds to and regulates three distinct classes of target genes. J. Biol. Chem. 285, 22059-22066 (2010).

26. Warner, M., Huang, B. \& Gustafsson, J. A. Estrogen receptor beta as a pharmaceutical target. Trends Pharm. Sci. 38, 92-99 (2017).

27. Muthusamy, S. et al. Estrogen receptor beta and 17beta-hydroxysteroid dehydrogenase type 6, a growth regulatory pathway that is lost in prostate cancer. Proc. Natl Acad. Sci. USA 108, 20090-20094 (2011).

28. Thelen, P., Wuttke, W. \& Seidlova-Wuttke, D. Phytoestrogens selective for the estrogen receptor beta exert anti-androgenic effects in castration resistant prostate cancer. J. Steroid Biochem. Mol. Biol. 139, 290-293 (2014).

29. Stettner, M. et al. The relevance of estrogen receptor-beta expression to the antiproliferative effects observed with histone deacetylase inhibitors and phytoestrogens in prostate cancer treatment. Mol. Cancer Ther. 6, 2626-2633 (2007).

30. Nilsson, S., Koehler, K. F. \& Gustafsson, J. A. Development of subtype-selective oestrogen receptor-based therapeutics. Nat. Rev. Drug Discov. 10, 778-792 (2011).

31. Nilsson, S. \& Gustafsson, J. A. Estrogen receptors: therapies targeted to receptor subtypes. Clin. Pharm. Ther. 89, 44-55 (2011).

32. Miura, Y. et al. Cloning and characterization of an ATBF1 isoform that expresses in a neuronal differentiation-dependent manner. J. Biol. Chem. 270, 26840-26848 (1995)

33. Grasso, C. S. et al. The mutational landscape of lethal castration-resistant prostate cancer. Nature 487, 239-243 (2012).

34. Sun, X. et al. Frequent somatic mutations of the transcription factor ATBF1 in human prostate cancer. Nat. Genet. 37, 407-412 (2005).

35. Sun, X. et al. Deletion of atbf1/zfh $\times 3$ in mouse prostate causes neoplastic lesions, likely by attenuation of membrane and secretory proteins and multiple signaling pathways. Neoplasia 16, 377-389 (2014).

36. Sun, X. et al. Additive effect of Zfh $\times 3 / A t b f 1$ and Pten Deletion on Mouse Prostatic Tumorigenesis. J. Genet. Genom. 42, 373-382 (2015).

37. Takahashi, S. et al. Noncanonical Wnt signaling mediates androgendependent tumor growth in a mouse model of prostate cancer. Proc. Natl Acad. Sci. USA 108, 4938-4943 (2011).

38. Ellwood-Yen, $K$. et al. Myc-driven murine prostate cancer shares molecular features with human prostate tumors. Cancer Cell 4, 223-238 (2003).

39. Dong, X. Y. et al. ATBF1 inhibits estrogen receptor (ER) function by selectively competing with AIB1 for binding to the ER in ER-positive breast cancer cells. J. Biol. Chem. 285, 32801-32809 (2010).

40. Li, M. et al. Upregulation of ATBF1 by progesterone-PR signaling and its functional implication in mammary epithelial cells. Biochem. Biophys. Res. Commun. 430, 358-363 (2013).

41. Zhao, D. et al. Zinc finger homeodomain factor Zfhx3 is essential for mammary lactogenic differentiation by maintaining prolactin signaling activity. $J$. Biol. Chem. 291, 12809-12820 (2016).

42. Kim, I. Y. et al. Raloxifene, a selective estrogen receptor modulator, induces apoptosis in androgen-responsive human prostate cancer cell line LNCaP through an androgen-independent pathway. Cancer Res. 62, 3649-3653 (2002).

43. Kumar, S. et al. Estrogen receptor beta ligand therapy activates PI3K/Akt/mTOR signaling in oligodendrocytes and promotes remyelination in a mouse model of multiple sclerosis. Neurobiol. Dis. 56, 131-144 (2013).

44. Pravettoni, A. et al. Estrogen receptor beta (ERbeta) and inhibition of prostate cancer cell proliferation: studies on the possible mechanism of action in DU145 cells. Mol. Cell. Endocrinol. 263, 46-54 (2007). 
45. Nakamura, Y. et al. Cyclin D1 (CCND1) expression is involved in estrogen receptor beta (ERbeta) in human prostate cancer. Prostate 73, 590-595 (2013).

46. Dey, P., Barros, R. P., Warner, M., Strom, A. \& Gustafsson, J. A. Insight into the mechanisms of action of estrogen receptor beta in the breast, prostate, colon, and CNS. J. Mol. Endocrinol. 51, T61-T74 (2013).

47. Dong, X. Y., Guo, P., Sun, X., Li, Q. \& Dong, J. T. Estrogen up-regulates ATBF1 transcription but causes its protein degradation in estrogen receptor-alphapositive breast cancer cells. J. Biol. Chem. 286, 13879-13890 (2011).

48. Dong, $X .-Y$. et al. Oestrogen causes ATBF1 protein degradation through the oestrogen-responsive E3 ubiquitin ligase EFP. Biochem. J. 444, 581-590 (2012).

49. Lin, C. Y. et al. Transcriptional amplification in tumor cells with elevated c-Myc. Cell 151, 56-67 (2012)

50. Yan, J. et al. Transcription factor binding in human cells occurs in dense clusters formed around cohesin anchor sites. Cell 154, 801-813 (2013).

51. Sboner, A. et al. Molecular sampling of prostate cancer: a dilemma for predicting disease progression. BMC Med. Genom. 3, 8 (2010).

52. Taylor, B. S. et al. Integrative genomic profiling of human prostate cancer. Cancer Cell 18, 11-22 (2010).

53. Rizza, P. et al. Estrogen receptor beta as a novel target of androgen receptor action in breast cancer cell lines. Breast Cancer Res. 16, R21 (2014).

54. Huang, B. et al. Differential expression of estrogen receptor alpha, beta1, and beta2 in lobular and ductal breast cancer. Proc. Natl Acad. Sci. USA 111, 1933-1938 (2014).

55. Matsumura, K., Tanaka, T., Kawashima, H. \& Nakatani, T. Involvement of the estrogen receptor beta in genistein-induced expression ofp21(waf1/cip1) in PC-3 prostate cancer cells. Anticancer Res. 28, 709-714 (2008).

56. Meyer, N. \& Penn, L. Z. Reflecting on 25 years with MYC. Nat. Rev. Cancer 8 , 976-990 (2008).
57. Suzuki, $H$. et al. Involvement of estrogen receptor beta in maintenance of serotonergic neurons of the dorsal raphe. Mol. Psychiatry 18, 674-680 (2013).

58. Bektic, J. et al. Androgen receptor regulation by physiological concentrations of the isoflavonoid genistein in androgen-dependent LNCaP cells is mediated by estrogen receptor beta. Eur. Urol. 45, 245-251 (2004). discussion 51.

59. Gehrig, J. et al. Prospects of estrogen receptor beta activation in the treatment of castration-resistant prostate cancer. Oncotarget 8, 34971-34979 (2017).

60. Andersen, R. J. et al. Regression of castrate-recurrent prostate cancer by a small-molecule inhibitor of the amino-terminus domain of the androgen receptor. Cancer Cell 17, 535-546 (2010).

61. Nakamura, H. et al. Genistein versus ICI 182, 780: an ally or enemy in metastatic progression of prostate cancer. Prostate 73, 1747-1760 (2013).

62. Karamouzis, M. V., Papavassiliou, K. A., Adamopoulos, C. \& Papavassiliou, A. G. Targeting androgen/estrogen receptors crosstalk in cancer. Trends Cancer $\mathbf{2}$, 35-48 (2016).

63. Thomas, C. \& Gustafsson, J. A. The different roles of ER subtypes in cancer biology and therapy. Nat. Rev. Cancer 11, 597-608 (2011).

64. Ma, G. et al. Zfhx3 is essential for progesterone/progesterone receptor signaling to drive ductal side-branching and alveologenesis in mouse mammary glands. J. Genet. Genomics. pii: S1673-8527(19)30048-7. (2019). https:/doi.org/ 10.1016/j.jgg.2019.03.003. [Epub ahead of print].

65. Nakajima, Y. et al. Estrogen exhibits a biphasic effect on prostate tumor growth through the estrogen receptor beta-KLF5 pathway. Mol. Cell. Biol. 36, 144-156 (2015).

66. Debnath, J., Muthuswamy, S. K. \& Brugge, J. S. Morphogenesis and oncogenesis of MCF-10A mammary epithelial acini grown in three-dimensional basement membrane cultures. Methods 30, 256-268 (2003).

67. Ran, F. A. et al. Genome engineering using the CRISPR-Cas9 system. Nat Protoc. 8, 2281-2308 (2013). 